\title{
The influence of folk art appreciation on modern art design
}

\author{
Zheng Lixia ${ }^{1, a}$ \\ ${ }^{1}$ Jiangxi college of foreign studies,NanChang,330099, China \\ azhenglixiajx@yeah.net
}

Keywords: Folk art; Aesthetic form; Modern art; Design influence; Research and discussion.

\begin{abstract}
The modern design needs the folk art to enrich and enrich its inside information, at the same time, it also has to innovate, make the design work not only has the national feeling, but also has the modern feeling. China folk art culture, is the Chinese native culture in Chinese civilization in the fertile soil of breeding, the continuation and development of modern communication, enlightenment Chinese design context, is a useful complement to the creation ideas and principles of modern art design of the China. This paper first describes the basic characteristics of folk art and modern art design and the basic situation, the analysis and study of the influence of folk art and modern art design and folk art to modern art design, the application of folk art in modern art design, and the modern art design to go the road of that nation. Art design is a reflection of a country's economic development level, science and technology development level, aesthetic level, but also a national cultural embodiment of art design needs innovation, but innovation is the foundation. Different ethnic groups have different artistic styles, aesthetic standards and customs, all in their own way to show their emotions. "Folk art is a kind of culture". It is a source of - cut art shapes, meaning is the basis of creative art, modern art design, and they cannot do without the development of folk art. The origin and foundation of all people should ask this art to absorb nutrition of this element of the body, in order to better development. No doubt, the folk art and modern design art in the pursuit of simple, concise summary, and philosophical concepts, there are a lot of communication and exchanges, Wang frozen points, we have a lot of space to deep mining. Connotation of folk art and modern design art is inexhaustible, inexhaustible reservoir of the house.
\end{abstract}

\section{Introduction}

The folk art in our country is rich and colorful, and is full of simple, pure and pure personality. The special characteristics of the folk fine arts determine that it has a great difference with the general sense of the pure art, so that it has a permanent artistic charm and vitality. Folk art is rooted in the masses of the people of the simple art, is the national folk producers to create their own practical art. Folk art contains deep cultural connotation, emotional factors, folk customs and folk way of thinking, and many other factors. Generally speaking, folk art is a practical art, practical purpose and requirements to the folk art to create strong cultural norms, an important aspect of practical significance has become the theme of folk art and art style. Folk art in the use of materials about natural materials "faithful to the material", "fit for purpose", derived from natural materials and simple faithful event as its foundation, emphasize the "adaptive apprentice of nature" faithful to the material for the purpose of creating some simple[1], pure and natural folk art. In the modern design, people also pay attention to the material from the nature. Although the modern design has been widely used in new technologies and new materials, but the designers inspired creative inspiration do not forget the use of natural materials, decorative style, the design intent is contained in the connotation of folk art style. Art is the pursuit of the product in the process of high quality of life, it is a kind of image to reflect the reality, but higher than a realistic social ideology, its species distribution is very wide, wide, including the form of literature, painting, sculpture, architecture, music, dance, drama, film, art a variety of art. The folk art is a branch of the art field, a flower. In two words before art on the crown of "folk", apparently with "palace of art", "noble art", "art of religion" and other types of art is out of the ordinary place, from which the attribute "folk" can be seen, the source of art and art activities, art, art display object the development trend and so on. So, we can draw such a 
conclusion that is "all in the formation and development of folk and popular traditional art and folk color art and skill, is a folk art." Zhang Daoyi was a "folk art" under such a definition, "folk art is a special category, especially in the process of historical development, mainly by the ordinary working people, the depths of the lower strata of the society, according to the needs of their own life, and fully integrated into the creation, appreciation and application, and the art of life form." As the world customs, culture and other aspects of the different years, has formed many types, a variety of styles of folk art forms to take Chinese around, for example, a Peking Opera (Opera), China (weaving), knot cutting (carving), Face book (painting). Folk art has the longest history, the most extensive region, the most numerous people, and to maintain the maximum limit of simple, primitive way of thinking and collective inheritance. It can be said that the formation of folk art, the history of the spread and development of human society, economic and cultural, aesthetic concepts, the history of the development of ideology[2].

\section{The relationship between folk art and modern art design}

Folk art style and modern design are intricately linked. Folk art as a form of art, it comes from the ancient Chinese culture for thousands of years of accumulation, with a great universality and popularity. With the wide range of folk activities, there has been a lot of attention to the internal spirit of the decorative patterns of expression. Folk paper-cut is widely used as a kind of animal or flower, in the form of indirect metaphor reflects the pursuit of the ideal of beauty. In the modern design, it is also widely used in the method of analogy, that is, the use of abstract graphics conversion metaphor specific things, so that the modern design more convincing. If the flag and emblem of the Macao Special Administrative Region, in the green design, full of peace and tranquility, a symbol of Macao Mishima three flower lotus, crystal white, rose from the calm sea, with features of Macao Aodang bridge like silver belt across about the pursuit of the sovereignty of People's Republic of China and said "one country two systems" five Venus over the distribution of graphic design and folk art in the pure, simple and vivid adornment meaning of something good wishes form is agree without prior without previous consultation. The modern art design, extensive use of graphic symbols and abstract deformation to the work performance of the "spirit", highlight the image of theme. The fusion of folk art connotation and modern design does have a similar nature of traditional and modern features of marriage, they are the same strain.

Folk art is the source of the development of modern art design in our country. There is a treasure house of art design in our country's folk art. Folk art is widely distributed to the people from generation to generation, continuity, so that the masses of monasteries, hand in, so subtle, empathy, and their blood melt together. China's modern art and design must be based on folk art, pay attention to the study of folk art, and establish the concept of modern art design of national development, in order to create a unique national characteristics of good works. In the art form in the sense of folk art, in the multi-dimensional space of order and order processing, focusing on the line, surface, texture and color, the irregular image of the organization to the symmetry of the tidiness, neat things organized, the natural form of images has a harmonious order. The creation of this form of beauty, in the form of modern art design will undoubtedly give people a new enlightenment. Folk art incorporates the abstract in like modeling language, like modern art design through "symbolic" graphics to convey information, to give people endless imagination space. In recent years, with the exchange of foreign culture, our country's folk art has been more and more attention. In modern art design[3], get inspiration from folk art and successful examples are many, such as fresh out of the 2008 Olympic Games emblem "Chinese India - dancing Beijing" is one of them, the design has been successfully adopted in folk arts "Pictorial seals" in the traditional cultural elements, the Chinese characters of the creative application, through the deep understanding of Chinese characters and calligraphy font Zhuanti, with the charm of the character "Jing", depicts people dancing style, to convey to the world the concept of "new Beijing, Great Olympics" at the same time, it will blow to the world of Oriental charm. 
The diversification of folk art. Folk art is the source of modern design. "People's life exists literature and art materials in mineral resources, this is a natural form of things is the rough stuff, but also the most vivid, the most basic things, from this point, they make all the text of art is the only source of all inferior by comparison, their character art inexhaustible." So people create the full of the public's folk art is the source of the modern design. China's modern design has been following the pace of international design, from eighty times to the present, China's design has not been positioning. China's modern design is also gradually to find their own should adhere to the direction of development, and that is the Chinese traditional elements in modern design. Traditional Chinese folk art and modern design are important to the combination of tradition and modern. And the best example is the opening ceremony of the 2008 Olympic Games. With auspicious clouds, flying, scroll and Tai Chi Chinese traditional elements, so that the opening ceremony of the brilliant, impressed the world hundreds of millions of viewers, profound culture of 5000 years show the most incisive. And because of the opening ceremony of the Chinese traditional elements of the show. The cheongsam, blue and white porcelain, Chinese China symbol spread around the world, the opening ceremony of the Chinese elements with more to reach the boiling point of the Olympic games. The combination of modern design and Chinese traditional elements, this is a classic use. The application of Chinese traditional elements in modern design is not only to inherit the spirit of Chinese traditional culture, it will give birth to the "Chinese elements" of Chinese cultural spirit, which will lay the confidence of Chinese brand to the world. The relationship between China traditional folk art and modern design is the same.

\section{The influence of folk art on modern art design}

The cultural origin of folk art. Folk art, which is an integral part of the national culture, is an integral part of the Chinese national culture, and is also the parent of the Chinese national culture and art. Its form is gorgeous, rich in variety, rich in connotation, and has a long history. Is being discussed by the scholars in the art world. Multi level and multi discipline research work on folk art is still in its initial stage. However, the exchange of Chinese and Western culture, the development trend of Chinese traditional culture, inspired people to the unprecedented enthusiasm of folk art, to create a new art style. In this social cultural background, folk art is like a magnet attracting us, waiting for us to explore.

The contribution of folk art to modern art in China. In the history of Chinese modern art, it is the first time to take root in the folk art and absorb the folk art, to change the artistic style of the artists in Jiefang District during the Anti Japanese war. At that time can not do a comprehensive study of folk art. Artists have not noticed the wider world of folk art and its cultural value. The real formation of the study, the study of the upsurge of folk art, is in 80s. The implementation of a comprehensive national policy, modern western culture and art and traditional culture in China collision, re-examine the traditional culture, many artists naturally turned to folk art, folk art of the discovery, exploration, have made outstanding contributions to finishing[4], has now entered the recovery status of national folk art culture era. The study of folk art, the creation of the new era of art as the purpose, folk artists and modern professional artists began to equal exchange, learning. This kind of research study, from the emotional, the concept of understanding and grasp of the folk art of temperament, spirit, connotation, cultural significance; study the concept of its form, form, technique, color, and then create. When the "folk hot" and "folk art" and other social thoughts influence on folk art as one falls, another rises, has become increasingly concentrated, and modern design, painting, sculpture and so on, have to absorb nutrients from folk art, folk art color elements and form elements have a profound impact on modern art. First of all, the connotation of our color Shuo Shuo: folk art, folk art color is based on the humanities, advocating plain natural and simple deep artistic conception, showing the local color and traditional complementary color market. Many famous advertising art designers is to succeed, not only because he has a modern design consciousness and mind class, because he also added many Chinese localized content in the advertisement design, features and foreign color exaggeration and different color in painting in the traditional structure of our country, is the most 
basic red hue contrast blue, yellow, or red, green and blue. The highest purity of color, after adjusting the artist between them with white or black area, after the interval, the color structure obtained the clear color composition of stable and uniform. The overall effect of color harmony, unity, the whole. Another color combination between Chinese people and the unity of harmony and harmony. Such as the Dunhuang mural color is the overall color contrast color in harmony on the basis of. Exactly the same Chinese "psychological rhythm beauty" to coincide.

The application of folk art spirit connotation in design creativity. Pray for survival, longevity and evil resisting disaster is the basic theme content of folk art. The concept of folk artists can be summarized as: "big", "live", "full", and "beauty"'. "Big" is a huge individual; "live" that is, "full" index of the amount of "beauty" refers to the comfort of the senses. The works created by this work are huge, full, harmonious, symmetrical and fresh form of beauty. This form of beauty and its spiritual connotation is still popular with the majority of people agree. Modern design for the use of folk art is to take its form, extend its meaning, to pass its god". The vivid continuation of folk art spirit connotation is the key. For example: there is a lot of folk art from the Taiji diagram derived from the "shape", such as: Pisces, bowl and snake rabbit etc.. They all expressed their prayers for the prosperity ". The yin yang philosophy all is derived and the God "'. Designers borrow Yin and Yang eight diagrams of the shape of the same time, it is more important to convey the spirit of its connotation. Folk art auspicious patterns, covering the subject matter content, plant, animal figures and abstract patterns rich, mostly with symbol and meaning, homonym, table number patterns Fu Lushou happiness and wealth auspicious; to create abstract imagination, exaggeration, special-shaped isomorphism modeling decoration performance a complete, complete, symmetrical, smooth decorative aesthetic feeling, leaving a large number of classic cultural symbols for us. As a symbol of the rich "year after year", a symbol of fertility "Lotus son", a symbol of a successful "Li yu tiao long men" etc.In the modern design, the use of auspicious patterns of folk art, both to produce new and unique visual effects at the same time highlight the national characteristics and cultural connotation of the product. Of course, "borrowing" is not equal to plagiarism. The designer must carry on the auspicious patterns, by cutting out the superfluous times to the aesthetic standards of Qucuqujing, reconstruction, the complementary harmony and other design elements, so as to create design works not only to retain the traditional connotation and characteristics of the times.

The application of folk art color in color design. The color symbol of folk art is strong. Green, red, yellow, white and black colors represent five basic elements, five directions, five season, and thus derived rich meaning. Such as red on behalf of the South fire, contains auspicious festive meaning; yellow on behalf of the central land, a symbol of wealth and honor. Folk artists have always attached great importance to the color symbolism to bring the spirit of power, so fond of red and yellow, so pure, strong auspicious color. The overall color style with decorative color with high purity and strong contrast, especially good at color contrast and juxtaposition of complementary collocation, put forward the "red with green, a piece of jade", "blue is not tied, yellow and white with the shoulder", "Purple bones is green band, with red and yellow update" color formula. Modern design, such as drawing on the customary use of these folk art color and color matching method, can make the traditional goods and folk old brand packaging color more visual impact, the folk characteristics at a glance. In addition, there are strong regional differences in the color of folk art. Such as Xiangxi's blue and white printed cloth is fresh, simple and clear, Guizhou Hmong clothing embroidery black backing colorful and gorgeous mysterious patterns. The use of different regions of the folk color elements will be more enhanced geographical features, it is suitable for use in the packaging of native products[5].

\section{The road of modern art design of nationalization}

The Chinese nation inclusive world advanced culture, good quality concept is the fundamental stand in the forest of the world culture. The development of a national art design is the background of the national cultural heritage. In the development of the national modern art design on the road, Japan and Northern Europe has never abandoned the national tradition, the Nordic art design is the perfect 
combination of national tradition and modern. Nordic design is the perfect combination of tradition and Modernity in the design principles of "functional" and "for the design of the public" design purposes. For example, although the Swedish designer emphasizes the function of modernist principles, but they pay more attention to decorative patterns, traditional and natural form, formed a new ceramic and glass design as the representative of the modern Swedish style "'. Japanese art is designed to take the road of nationalization. In 1970s, the Japanese art design level has reached a staggering height. For example, Mistake Sato Akihito is a pair of feet in Japanese culture extension line, following a new generation of graphic designer Tanaka a light after the older generation of graphic designers on the design stage. His design works inherit Japanese Dynasty literary aesthetic consciousness, at the same time with chilled feeling. He not only inherited the Japanese culture in the distant, quiet, elegant, gentle national style, this style will be one step closer to perfect and enrich the essence of Japanese culture, refining the spiritual connotation. The Chinese nation is an indispensable part of all ethnic groups in the world, the modern art design, we should establish their own self-confidence, based on our national traditional ethnic art from soil, especially in the essence of folk art, took the own development path.

\section{Summary}

The folk art of vivid, free, romantic, interesting art form, is a reflection of cultural and psychological characteristics of the Chinese nation, conveyed in ethics and aesthetic ideal, create awareness of the spiritual pursuit. Providing rich mineral spring for the development of contemporary art design, it can also play a positive role in the development of the sustainable and healthy development of art design. The modern art design in the future, should pay attention to the inheritance and development of folk art, the excellent folk culture and modern science and technology combine to create a worthy of our great era, there are characteristics of modern design style to China.

\section{References}

[1] Luo Haiying. To enhance the cultural identity is the inevitable way to the development of folk art -- a case study of Longmen peasant painting [J]. art observation. 2016 (08).

[2] Han Geng, Mazhiyao. "Folk art and art design in the context of intangible cultural heritage" is to study on the development of folk [J].2014 (02).

[3] cattle Zaixia. Adhere to the folk art and the innovation and development of the [J]. stage. 2014 (02).

[4] Chen Fang. The aesthetic implications of [J]. stage of folk art in China. 2014 (02).

[5] Liu Qiang. Xuzhou folk art resources into several issues of educational resources [J]. art and technology. 2014 (01). 